\title{
Hot-Twist Ductility of High-Chromium Ferritic Steels*
}

\author{
By Fujio Tsukamoto** and Takashi Suzuki***
}

\section{Synopsis}

The effect of important metallurgical factors such as chemical composition, microscopic structure and grain size on the hot-twist ductility of AISI-446 type and some other highchromium ferritic steels was investigated by the hot-twist test with bar specimens rotated at $200 \mathrm{rpm}$ at a temperature ranging from 800 to $1,250^{\circ} \mathrm{C}$. The results obtained were :

(1) The steels which have a ferritic single-phase structure show a fairly high twist value and convex-type twist curves at specific test temperatures. On the contrary, the two-phase $(\alpha+\gamma)$ structure in the same range of test temperature shows a low twist value and concave-type curves.

(2) Carbon and nitrogen are the most harmful elements and especially the addition of carbon plus nitrogen up to abous $0.2 \%$ rapidly decreases the twist value.

(3) Silicon lowers the twist value of the low-nitrogen $25 \%$ chromium steels, while the twist curve shifts to the higher temperature side in the 446-type steel with about $0.2 \%$ nitrogen.

(4) The twist value of the low-carbon and low-nitrogen high-chromium steel decreases as the chromium content it increased.

(5) There is little difference in twist values between airmelted and vacuum-melted steels which have similar chemical compostion.

(6) The grain coarsening due to the elevation of annealing temperature lowers the twist value.

\section{Introduction}

Studies on the hot-workability of high chromium ferritic steels are very few because these steels usually exhibit a lower resistance to deformation ${ }^{1)}$ and a hot workability superior to those of austenitic stainless steels. However, in the practical hot working process, the occurrence of remarkable cracking has been experienced with these steels in spite of low resistance to deformation, especially in the piercing operation of seamless tubes with the Stiefel-Mannesmann tube mill. It is believed that this is due to ductility at working temperatures.

It is well-known that the hot ductility is decreased generally in the case of the two-phase structure at working temperatures in most metals, and as high-chromium ferritic steels such as AISI 446 have mostly the two-phase structure at elevated temperatures depending on chemical composition, it is presumed that the hot ductility is reduced for this reason.

From the viewpoint mentioned above, the present investigation was made into the effects of important metallurgical factors such as chemical composition, microscopic structure and grain size on the hot-twist ductility of high-chromium ferritic steels.

\section{Specimen and Test Procedure}

The specimens for the experiments were prepared on the basis of Type 446 high-chromium and nitrogen steel $(0.07 \% \mathrm{C}, 25.5 \% \mathrm{Cr}, 0.5 \% \mathrm{Si}$, $0.7 \% \mathrm{Mn}, 0.2 \% \mathrm{~N})$, from heats made by air- or vacuum-melting, and varied in the alloying elements such as carbon, nitrogen, silicon and chromium. A basic-lined high-frequency induction furnace with $200 \mathrm{~kg}$ capacity, was used for the air melting. In order to minimize the variations such as melting practices and other elements, each heat was deoxidized by Fe-Ca-Si $0.2 \%$ and ingots, $75 \mathrm{~kg}$ to $100 \mathrm{~kg}$ were poured one by one from the same heat after further additions of only one objective element step by step. A vacuum induction furnace with $100 \mathrm{~kg}$ capacity, was used, besides, for the vacuum melting and one $100 \mathrm{~kg}$ ingot was poured from each heat. All ingots were forged and rolled into round bars $16 \mathrm{~mm}$ in dia. and then these bars were water-quenched from $750^{\circ} \mathrm{C}$ after annealing for $1 \mathrm{hr}$ and used for tests. Table 1 shows the chemical composition of the specimens.

Table 1. Chemical composition of specimens subjected to hot-twist test

\begin{tabular}{|c|c|c|c|c|c|c|}
\hline \multirow{2}{*}{$\begin{array}{l}\text { Specimen } \\
\text { marks }\end{array}$} & \multicolumn{4}{|c|}{$\begin{array}{c}\text { Chemical } \\
\text { composition } \%\end{array}$} & \multirow{2}{*}{$\begin{array}{l}\text { Transformation } \\
\text { temperature } \\
\text { of } a \text { to } a+\gamma\left({ }^{\circ} \mathrm{C}\right)\end{array}$} & \multirow{2}{*}{$\begin{array}{l}\text { Melting } \\
\text { process }\end{array}$} \\
\hline & C & $\mathrm{Cr}$ & $\mathrm{Si}$ & $\mathrm{N}$ & & \\
\hline $\mathrm{RX}-31$ & 0.08 & 25.62 & 0.45 & 0.18 & 1150 & \multirow{9}{*}{ Air-melt } \\
\hline $\mathrm{RX}-2$ & 0.025 & 27.61 & 0.70 & 0.21 & 1200 & \\
\hline RX-33 & 0.16 & 52.02 & 0.45 & 0.22 & 1100 & \\
\hline RX-34 & 0.22 & 24.62 & 0.45 & 0.22 & 1100 & \\
\hline $\mathrm{RX}-5$ & 0.07 & 25.51 & 0.37 & 0.054 & 1200 & \\
\hline $\mathrm{RX}-6$ & 0.06 & 25.50 & 0.51 & 0.38 & 1150 & \\
\hline $\mathrm{RX}-8$ & 0.07 & 25.72 & 1.53 & 0.21 & 1200 & \\
\hline $\mathrm{RX}-10$ & 0.07 & 25.72 & 2.50 & 0.21 & 1250 & \\
\hline $\mathrm{RX}-7$ & 0.07 & 25.51 & 1.34 & 0.054 & $*$ & \\
\hline $\mathrm{RX}-\mathrm{V} 1$ & 0.06 & 25.80 & 0.44 & 0.26 & 1150 & \multirow{6}{*}{ Vacuum-melt } \\
\hline $\mathrm{RX}-\mathrm{V} 3$ & 0.012 & 25.11 & 0.39 & 0.008 & $*$ & \\
\hline $\mathrm{RX}-\mathrm{V} 5$ & 0.06 & 25.60 & 0.40 & 0.046 & 1200 & \\
\hline $\mathrm{RX}-\mathrm{V} 7$ & 0.011 & 25.69 & 0.52 & 0.022 & $*$ & \\
\hline $\mathrm{RX}-\mathrm{V} 16$ & 0.014 & 29.69 & 0.49 & 0.009 & $*$ & \\
\hline $\mathrm{RX}-\mathrm{V} 17$ & 0.015 & 34.41 & 0.45 & 0.010 & $*$ & \\
\hline
\end{tabular}

The measurement of hot-twist ductility was carried out by the twist test recognized as the most excellent method up to this time.2)3) Briefly the twist test consists of heating and holding a specimen round bar at a desired temperature, clamping one end of the specimen and twisting the other end, and recording the number of twists required for fracture. The hot-twist ductility of materials

\footnotetext{
* Lecture delivered before the 61st Grand Lecture Meeting on April 1961 in Tokyo. Japanese text was printed in "Tetsu to-Hagané" (Journal, Iron and Steel Institute of Japan) Vol. 47, No. 11, pp. 1602-1606.

** Manager of Kawasaki Plant, Nippon Metal Industry Co., Ltd., Dr. Eng.

*** Assistant Chief Metallurgist, Kawasaki Plant.
} 
at elevated temperatures is estimated by the magnitude of that number namely twist value.

The hot-twist testing apparatus used in the present expariments has the capacity of $10 \mathrm{~kg}-\mathrm{m}$, and tests were done at a rotation speed of 200 r.p.m. after holding a specimen of $8 \mathrm{~mm}$ in diameter of parallel part and $40 \mathrm{~mm}$ in length for $20 \mathrm{~min}$. at desired temperatures ranging from $800^{\circ}$ to $1,250^{\circ} \mathrm{C}$. Because it is usually considered that in the twist test, the twisting moment and twisting energy to fracture do not show the practical workability in forging,3) only the number of twists to fracture was determined but the torque was not measured. To confirm the reliability and accuracy of the apparatus, the standard deviations of number of twists were calculated from the result of twist tests at $1,150^{\circ} \mathrm{C}$ on two specimens, RX-33 and RX-5 in Table 1. Table 2 showing the results indicates standard deviations of less than $10 \%$ of the value without regard to twist values. It is, therefore, believed that the measurement is accurate enough to make a comparative study of hot-twist ductility.

Table 2. Standard deviation of hot-twist test

\begin{tabular}{c|c|c|c|c} 
Specimens & Test temperature $\left({ }^{\circ} \mathrm{C}\right)$ & $n$ & $\bar{x}$ & $s$ \\
\hline $\mathrm{RX}-33$ & 1150 & 10 & 16.7 & 1.33 \\
$\mathrm{RX}-5$ & 1150 & 10 & 404.1 & 36.4
\end{tabular}

The photograph in Photo 1 illustrates the appearance of specimens after twist tests in the case of a standard 446 steel (RX-31) and a low-carbon low-nitrogen steel exhibiting high hot-twist ductility (RX-V7). On specimens over 100 turns in twist value, many irregular protuberances are observed on the surface and the specimens do not easily fracture while the section becomes thinner.

\section{Influence of Alloying Element}

\section{Carbon and Nitrogen}

Fig. 1 shows the influence of carbon content on a level of $0.2 \%$ nitrogen and nitrogen content on a level of $0.07 \%$ carbon on the twist value of the samples air-melted.

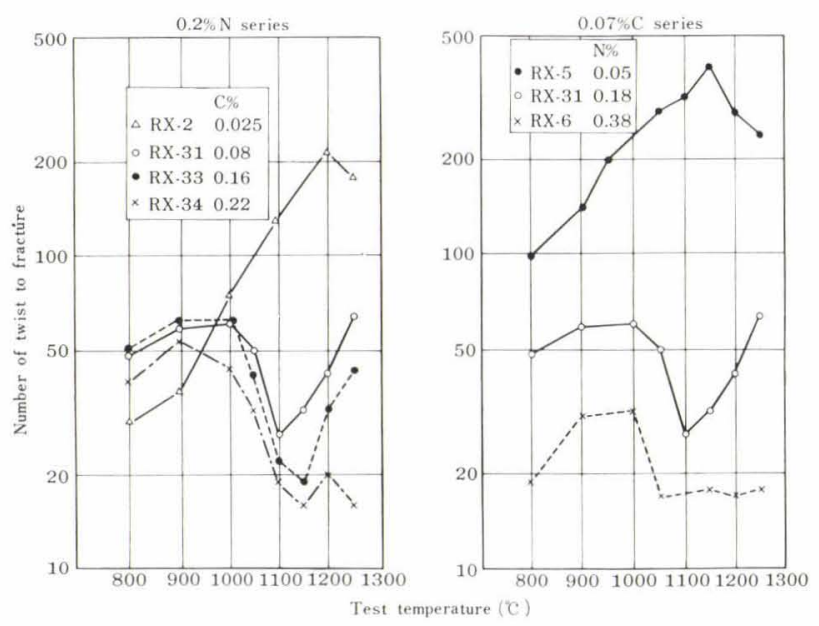

Fig. 1. Effect of $\mathrm{C}$ and $\mathrm{N}$ content on hot-twist ductility of AISI type 446 steels

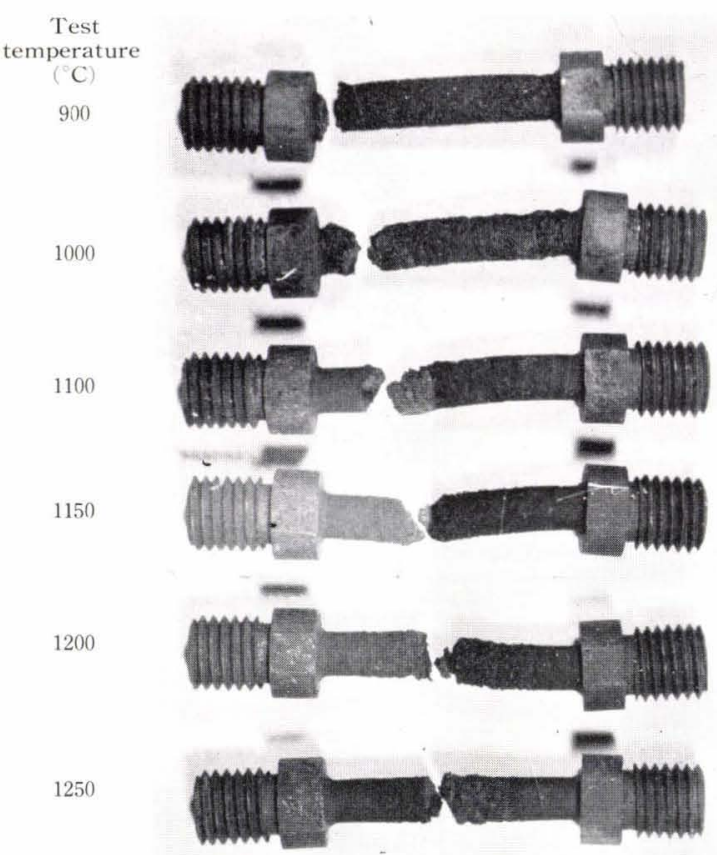

RX-31

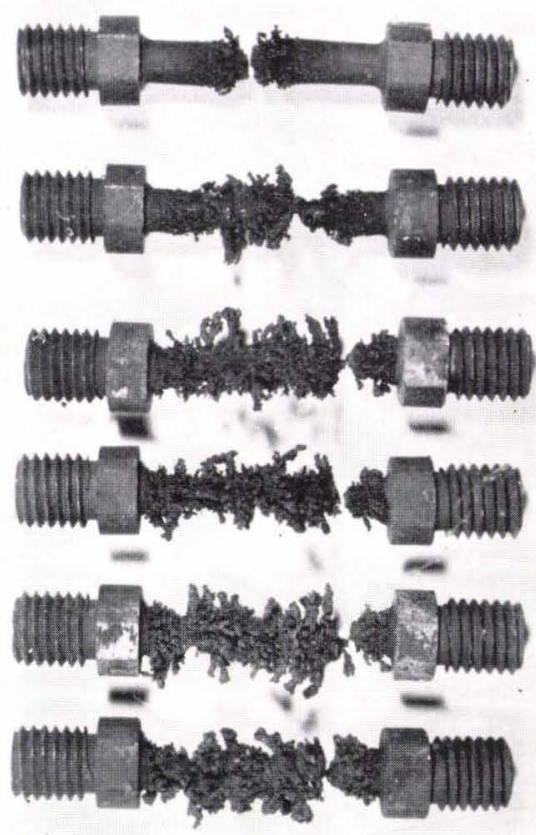

Photo 1.

Appearance of specimens after hot-twist test 
In general, the twist value drops with the increase of the carbon content. This tendency becomes remarkable as the test temperature is increased. The nitrogen also decreases the twist value. These results agree with the results shown by Contractor and Morgan. ${ }^{4}$

In Fig. 1, the type of twist curve may be divided into two groups, namely, convex and concave types against the test temperatures. The convex type twist curve is observed in the case of low-carbon and low-nitrogen steels, which show an almost fully ferritic structure and high twist values generally throughout the range of temperature in tests.

From the result of microscopic examination of specimens, it is observed that the intragranular fracture occurs at temperatures below the temperature of maximum twist and, on the other hand, the intergranular fracture appears as the temperature of maximum twist is exceeded. This phenomenon agrees well with the results of experiments on carbon steels reported by Clark and Russ.5) Moreover, it seems that the temperature of maximum twist becomes higher as the carbon and nitrogen contents are decreased.

The concave type twist curve is observed in the case of materials, which have generally low twist values and the transformation of $\alpha / \alpha+\gamma$ at elevated temperatures. In this case, the twist value

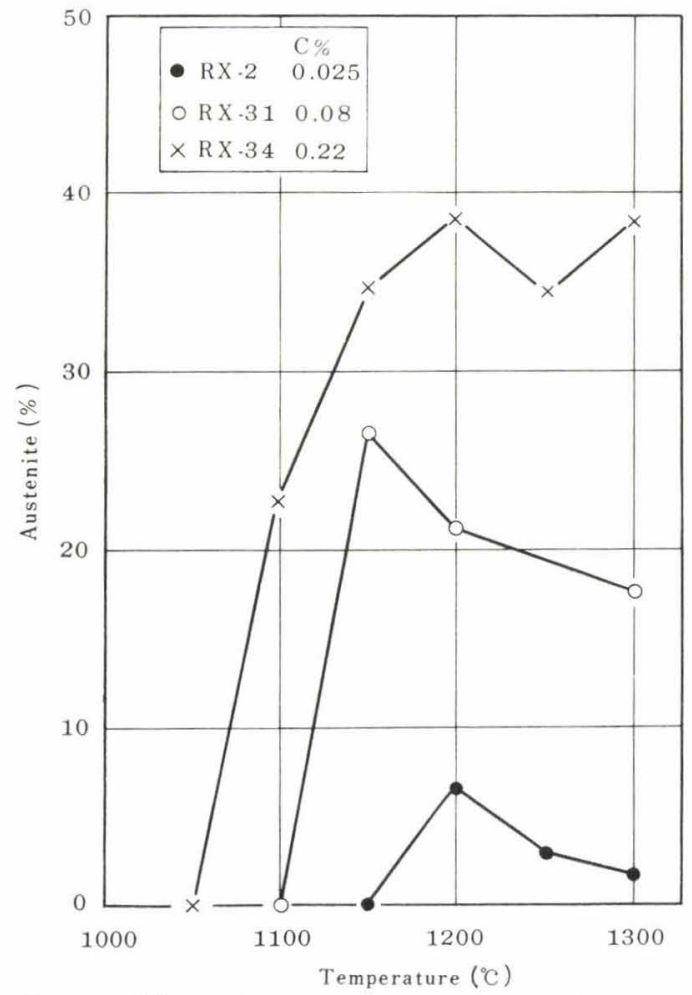

Fig. 2 Effect of the $\mathrm{C}$ content and heating temperature on the austenite percentage in AISI type 446 steel begins to decrease between the temperatures of 900 and $1,000^{\circ} \mathrm{C}$, as free carbide and nitride are dissolved into the ferrite matrix, and falls minimally at the transformation temperature, and then beyond this temperature tends to increase again in general as the amount of austenite decreases. From Fig. $2,^{6)}$ which shows the effects of heating temperature on the formation of austenite on Type 446 steels containing different carbon contents, it is clear that, in the field of two-phase structures, the amount of austenite is decreased gradually with an increase in temperature with low carbon steels such as $0.08 \%$ carbon, while there are no remarkable changes on high-carbon steels such as $0.2 \%$ carbon. Therefore, the increase of twist value beyond the transformation temperature on RX-31 and 33 in Fig. 1 is due to the increase in the amount of austenite, whereas on RX-34 which has no change of amount of austenite the twist value is almost constant.

Since it was found from the results shown in Fig. 1 that carbon and nitrogen markedly lower the hot-twist ductility of Type 446 steel, further experiments were carried out in the same way by samples melted in air or vacuum, which contain different quantities of carbon and nitrogen

As shown in Fig. 3, it is evident that the hottwist ductility is decreased rapidly with increasing $\mathrm{C}+\mathrm{N}$ if the result of experiments is arranged at each temperature on the effects of carbon plus nitrogen. It is observed that the effect of carbon plus nitrogen is remarkable in the case of a small quantity of $\mathrm{C}+\mathrm{N}$ and the decrease of ductility becomes less when the content exceeds $0.2 \%$. The difference between twist values of steels melted in air and in vacuum is, moreover, not seen in this result.

\section{Silicon}

In the case of a fully ferritic structure with lownitrogen content, the silicon lowers the twist value as shown in Fig. 4. However, the twist curve is shifted to higher temperatures with the increase of silicon content on Type 446 steels containing about $0.2 \%$ nitrogen. Therefore, depending on test temperatures, the effect of silicon is different and, for example, the addition of silicon tends to increase the twist value at $1,100^{\circ} \mathrm{C}$ while the twist value is lowered beyond a temperature of $1,200^{\circ} \mathrm{C}$.

This is based on the fact that the transformation temperature of $\alpha / \alpha+\gamma$ is raised with the increase of silicon content.

\section{Chromium}

The comparison between twist values of 25 to $35 \%$ chromium steels with low-nitrogen and lowcarbon content is shown in Fig. 5, and the result indicates that the hot-twist ductility is reduced with the increase of chromium content. 


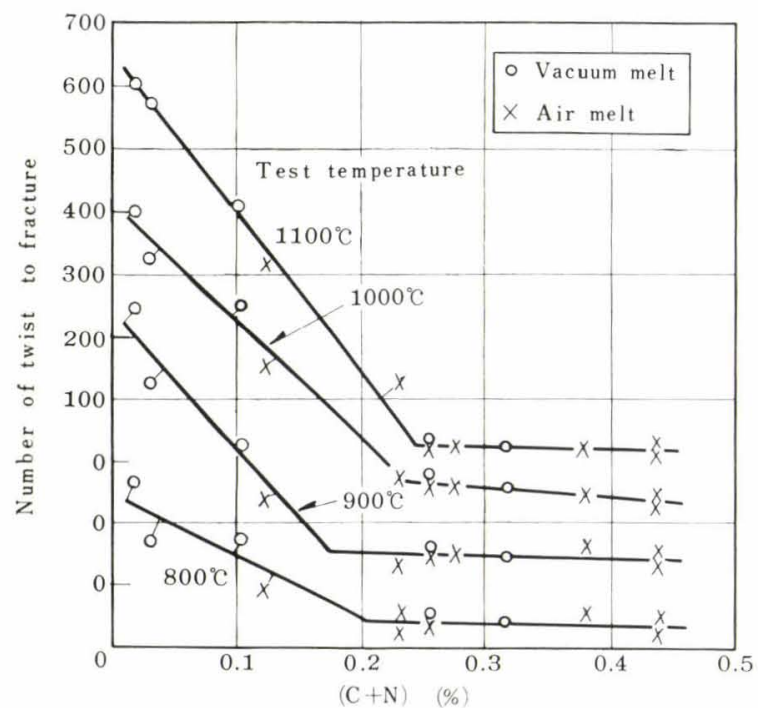

Fig. 3 Effect of $(\mathrm{C}+\mathrm{N})$ content on hot-twist ductility of $25 \% \mathrm{Cr}$ steel

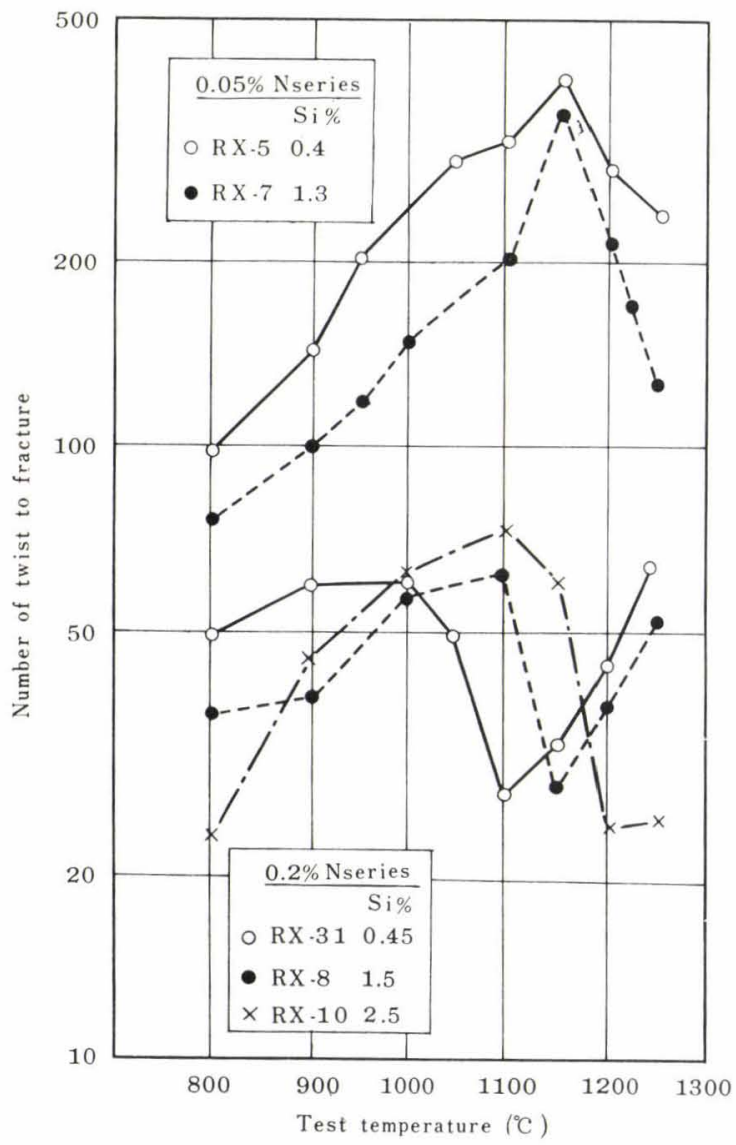

Fig. 4 Effect of Si content on hot-twist ductility of $25 \% \mathrm{Cr}$ steel containing low and high $\mathrm{N}$

\section{Effect of Annealing Temperature}

The results of experiments mentioned above were obtained from the hot-twist test on the samples water-quenched after being annealed at $750^{\circ} \mathrm{C}$ for $1 \mathrm{hr}$. However it is, of course, expected that the hot-twist ductility is affected by variables in processing, annealing temperature, grain size, etc. It is well-known that the remarkable grain coarsening, which results of heating at elevated temperatures, tends to reduce cold workability with high-chromium ferritic steels. In order to understand such an effect of grain size on hot-twist ductility, a series of hot-twist tests was carried out on samples water-quenched after being held at various annealing temperatures ranging from 750 to $1,300^{\circ} \mathrm{C}$ for $1 \mathrm{hr}$., on steels of standard type 446, RX-V1, and low-nitrogen type RX-V5. The sample RX-V1 has a two-phase structure at elevated temperatures and a transformation point of $\alpha / \alpha+\gamma$

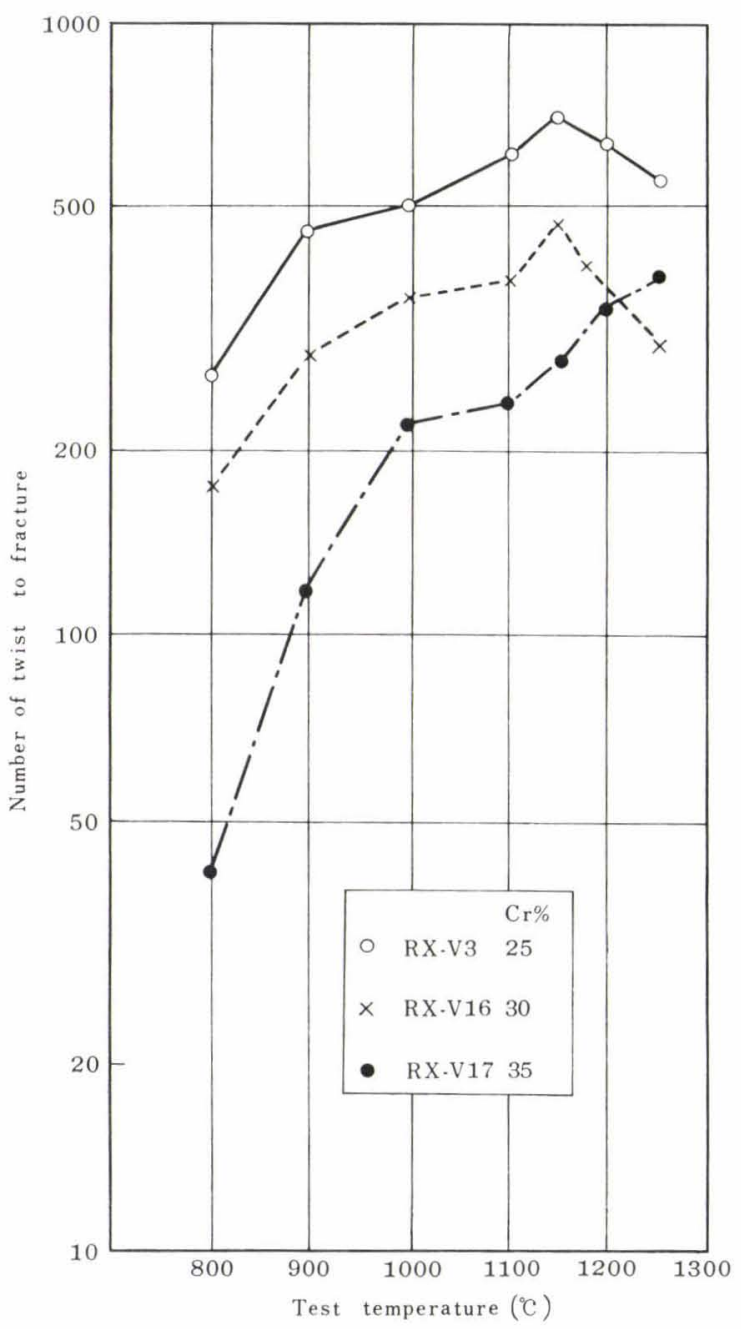

Fig. 5 Effect of $\mathrm{Cr}$ content on hot-twist ductility of low C, low-N ferritic steel 
between $1,100^{\circ} \mathrm{C}$ and $1,150^{\circ} \mathrm{C}$, while $\mathrm{RX}-\mathrm{V} 5$ has a composition exhibiting fully ferritic structure without the precipitation of austenite phase in almost all cases.

As shown in Fig. 6, the results of experiments indicate that the sample RX-V5 shows a convextype twist curve against test temperatures except specimens annealed at more elevated temperatures, while RX-V1 exhibits a concave-type curve. On both samples, the hot-twist ductility is decreased as the annealing temperature is raised which consequently results in grain coarsening. The tendency is more remarkable with RX-V5, an almost fully ferritic steel with a tendency toward marked grain growth. However, the twist value is almost constant below the annealing temperatures of $1,000^{\circ} \mathrm{C}$ on $\mathrm{RX}-\mathrm{V} 1$ and $1,100^{\circ} \mathrm{C}$ on RX-V5. These temperatures correspond to the temperatures showing the maximum twist value for each of the samples annealed at $750^{\circ} \mathrm{C}$, and, thus, it is believed
Fig. 6 .

Effect of annealing temperature on hot-twist ductility of AISI type 446 (RX-V 1) and $25 \% \mathrm{Cr}$ steel (RX-V 5)

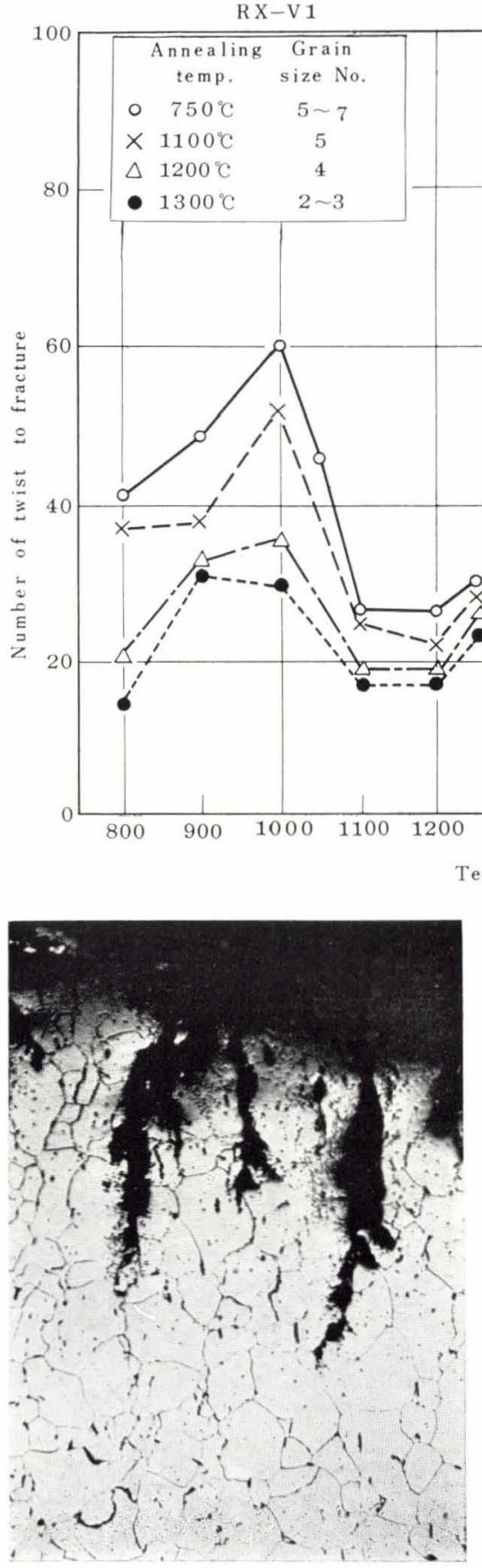

(a)

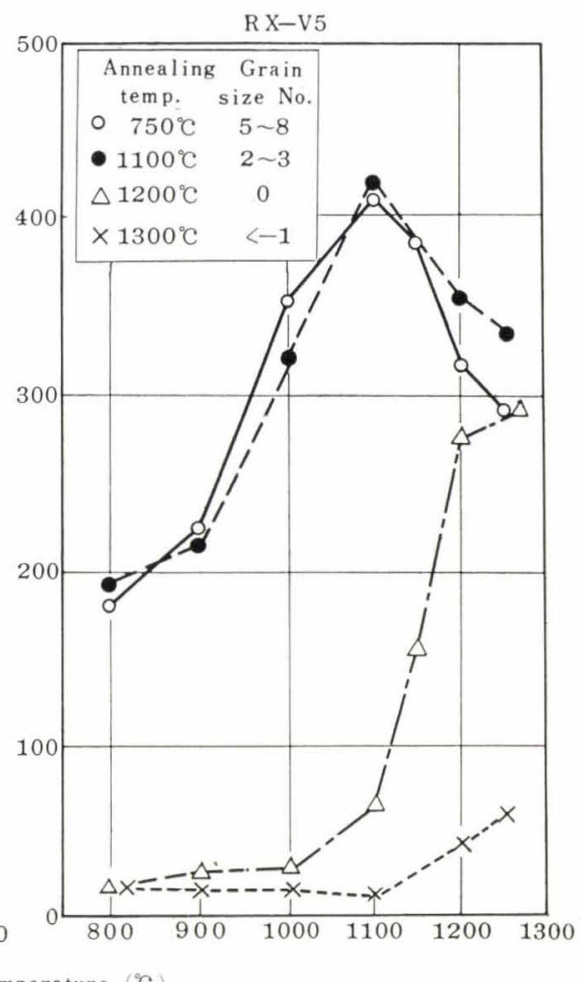

Test temperature $\left({ }^{\circ} \mathrm{C}\right.$

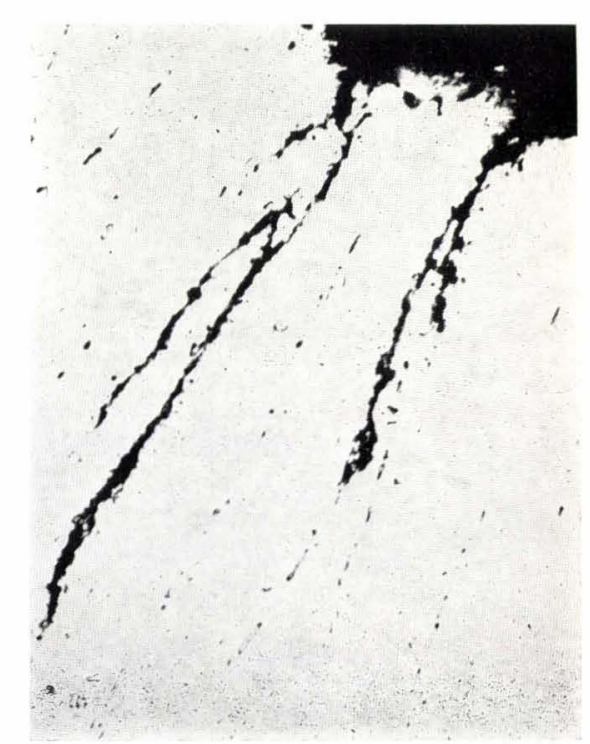

(b)
Photo 2.

Fractured RX-V 5 hot-twist specimens tested at $1,000^{\circ} \mathrm{C}(\times 100)$

Preheatment : (a) $1,000^{\circ} \mathrm{C}$, (b) $1,300^{\circ} \mathrm{C}$ Etched electrolytically with $10 \%$ oxalic acid solution 
that the influence of annealing temperature or grain size is almost negligible in the case of annealing in the intragranular fracture region below these temperatures. However, the loss of hot-twist ductility which is observed in the case of annealing in the intergranular fracture region above the temperature of maximum twist is not observed.

Photo 2 shows the microscopic structure of sample RX-V5 on which the hot-twist test is conducted after heating at $1,000^{\circ} \mathrm{C}$ and $1,300^{\circ} \mathrm{C}$ for $1 \mathrm{hr}$. followed by water-quenching, and it is clear that the type of fracture transfer from intragranular fracture to intergranular with the increase of annealing temperature.

\section{Conclusion}

In regard to the hot-twist ductility of highchromium ferritic steels, the following conclusions can be obtained from the results investigated by the hot-twist test at temperatures of $800^{\circ} \mathrm{C}$ to $1,250^{\circ} \mathrm{C}$ on the effect of chemical composition, microstructure and grain size:

(1) The materials which show the ferritic singlephase structure at test temperatures exhibit, generally, fairly high twist values and convextype twist curves against test temperatures. In this case, the nature of failure is transgranular fracture up to the temperature of maximum twist and changes to intergranular fracture as this temperature is exceeded. On the other hand, the materials which have the transformation of $\alpha / \alpha+\gamma$ in the range of test temperatures exhibit, generally, low twist values and concave type twist curves against test temperatures, and also the temperature of minimum twist nearly corresponds to the transformation temperature.

(2) Therefore, with the steels which have the ferritic single-phase structure, the hot-working process should be conducted at temperatures below the temperature of maximum twist, while with the steels which have the two-phase structure the processing at temperatures near the transformation point should be avoided. The temperatures of the hot working process should be adjusted in the low temperature range from $900^{\circ} \mathrm{C}$ to $1,000^{\circ} \mathrm{C}$ if the resistance to deformation is suitable, or in the temperature range from $1,200^{\circ} \mathrm{C}$ to $1,250^{\circ} \mathrm{C}$ if the resistance to deformation is serious.

(3) As for the chemical composition of $25 \%$ chromium steel, carbon and nitrogen are the most harmful elements which lower the twist value. The addition of carbon plus nitrogen up to about $0.2 \%$ rapidly decreases the twist value. However, by further addition the twist value is not so affected. Twist values show a convex-type twist-curve up to $0.2 \% \mathrm{C}+\mathrm{N}$ and beyond $0.2 \%$, a concave-type twistcurve is observed.
With low-nitrogen $25 \%$ chromium steel, the silicon lowers the twist value, while on the Type 446 steel with about $0.2 \%$ nitrogen content both maximum and minimum values of the twist curve shift to the higher temperature side with the increase of the silicon content. This corresponds to the moving of the transformation temperature of $\alpha / \alpha+\gamma$ to higher temperatures as the silicon content is increased.

With the low-carbon and low-nitrogen highchromium steel, the twist value is decreased as the chromium content is increased.

The difference of twist values between air- and vacuum-melted steels which have the similar chemical composition can not be observed.

(4) The grain coarsening due to the elevation of annealing temperature lowers the twist value. Though the effect is not so great with two-phase steels, twist values are markedly decreased with ferritic single-phase steels having a tendency toward remarkable grain growth, because intergranular fracture appears at lower test temperatures when they are annealed at temperatures in excess of the temperature of maximum twist.

\section{REFERENCES}

1) K. Inoué : Tetsu-to-Hagané, 41 (1955) 506, 583, 839.

2) T. Morishima: Tetsu-to-Hagané, 41 (1955) 1069.

3) G. Wallquist, J. Carlen: Rev. de Mét. LVI No. 6 (1959) 268.

4) G. Contractor, W. Morgan : Iron Age, Nov. 13 (1958) 142.

5) C. Clark, J. Russ: Metals Technology 12 (1945) Dec. 1839.

6) F. Tsukamoto, T. Suzuki : Journal of the Japan Institute of Metals, 25 (1961) 811. 